\title{
Science Research and Patenting of Innovations
}

\author{
Alexander Bolonkin
}

\begin{abstract}
At the present time the USA's Federal Government spends big tax monies for Scientific Research and Development (R\&D). How to best organize this vast governmental activity, how to best estimate its ultimate utility and profitability (real and potential), how to best increase efficiency of innovation and production, how to best estimate the worth of new discoveries and innovations, how to properly fund R\&D of new concepts and innovations, and how to correctly estimate their results, how to improve a patenting all these macro-problems are important for successful planning of scientific research, new systems- these are all complex and pressing questions that require answers if further industrial progress and scientific improvements are ever to be! The authors consider these some major-system problems and offer many remarkable innovations in organization, estimation, suggestions for entirely new research efficiency criteria, development, new methods for assessments of new ideas, innovations in science and industry, and new methods in patenting technology.
\end{abstract}

Index Terms-Organizing scientific research, planning of research, funding research, funding new ideas (concepts), funding inventions and innovations, estimating research cost, assessment of research results, research efficiency criteria, innovation in organizing of scientific $R \& D$, patenting

\section{INTRODUCTION}

Since the beginning of the $20^{\text {th }}$ Century, science discoveries and improving technology have held the main role in human progress. Humanity has amassed more knowledge than during all previous centuries. People researched aerodynamics, flight dynamics and the design of aircraft. Trained people developed rocket theory and traveled into outer space and landed living people on the Moon by 20 July 1969 . Organized research focused on nuclear physics began the exploration of nuclear energy and the creation of powerful computers, which help with the further fast-paced study of Nature. Astronomy's devices allow humans to see and study extra-Solar System planets, possibly even worlds inhabited with forms of life, located millions of light-years beyond our homeland, the Earth.

The power and influence any modern ecosystem-State in our world has is defined by its science, technology, and industry capabilities. The USA is a world leader because, for many years the USA's industry and national government spent more money than any other country on R\&D, science-based technical innovations. For example, the USA funds space research more than all other countries combined. Until recently, the all the main scientific advances in space, aviation, and computers originated in the USA.

If the USA's citizens still desire to continue to be science and technology's world leader, they must continue this practice

A.A. Bolonkin worked for many years within the USA's Federal Government entities (scientific laboratories of NASA, Air Force), and USSR and USA universities and industry. and further refine this public and private policy. However, it is possible when the country will get moving is when it has competitors and takes part in a peaceful competitive struggle. Men on our nearby Moon became possible because the former USSR launched the first satellite (4 October 1957), commencing humankind's Space Age, and the USA's leaders at that critical time clearly understood the USA had temporarily lost global leadership in the important field of science and technology. Only in 1969, after the first manned flight to the Moon, did the USA return to undoubted leadership in space exploration and exploitation development. That program effectively ended in 1972. However, before collapse (1991) the USSR launched more satellites than all the rest of the World's space-faring ecosystem-States together, including the USA! The USA decided to restore this program only when China, that is the PRC, publicly announced its $21^{\text {st }}$ Century program for a manned Moon exploration.

The second very important side of scientific R\&D is the efficient use of available funding. The financing of any project is limited everywhere, every time. Unlimited funding is inconceivable. The right organization of scientific funding and research is a very important element of scientific progress. That includes: Organization and careful selection of the most feasible prospective ideas and innovations for research, selection of a "can do" principal investigator - scientists who are the authors or enthusiasts of this idea, its champion, a real hard-headed estimation of the macro-project cost, potentially reachable results, and practical application perspectives.

All these problems are very complex investigations. However, there are common criteria that help to solve these problems of selection and comprehensive organization, and which can save a lot of taxpayer money and achieve practical success in short period of time.

The investigation of these macro-problems is impossible without consideration of current systems of research and frank criticism of its disadvantages. The author suggest new criteria and new forms of organizing science funding that were tested and/or applied in limited particular cases herein, and which show a high specific efficiency. He also offers new criteria for evaluation of science results which allows more evenly for an observer to estimate the honesty of finished scientific work reports by specialists and to separate pseudo-scientific or non-honest works from real ones.

For customers, leadership and management is also very important for correct estimation of the cost of an offered research, a capability of principal investigator, group, or organization to do this research. Unfortunately, the practice shows mistakes occur very often and they can easily cost millions of USA Dollars (and the EU's Euros)! Herein, author suggests a straight-forward set of simple rules that will permit avoidance of the big strategic mistakes and big awkward and embarrassing tactical slips in the planning of future research efforts. 
The human presence is very important in the selection and distribution of limited monetary funding. In many organizations we observe and comment on the situation when large government money distribution-money shifted from all national taxpayers - is channeled by the directives of just one man. As a result, he or she begins to give money to his/her friends, to his/her colleagues or worse - to take bribes. Such a person keeps elementary information about the activities of his/her organization secret. Author, herein, offers a method for the best selection to foil this insidious practice, making it exceedingly difficult to initiate or, if revealed, to continue.

\section{HOW SUPPORT OF NEW CONCEPTS}

The monetary support of new aviation and extra-terrestrial space concepts is the basic element of humankind's ongoing scientific and technical progress. All useful things, which we see around us every day, were developed from new concepts, ideas researched in the rather recent past. This fact is gracefully, eloquently, and comprehensively outlined in [1]. But, let us consider the state of affairs now existing.

Science and technology are very complex and have a very high-level presence globally nowadays. The production of new valid concepts and ideas, and the effort to fully substantiate them, can ONLY be done nowadays by highly educated people, not by tinkerers and private-sector mutterers. The USA has hundreds of thousands of conventionally-trained scientists of every stripe possible. New concepts and ideas are generated only by a very few talented (genius-level) people supported by skilled workers. They are but a small percentage of every thousand scientists. That requires (from them) very much time and hard work. That is not going to be fully paid time in government or company laboratories. The Government and private laboratories develop ONLY known concepts and ideas because their purpose is to get the maximum profit in the shortest time; that means to produce and substantiate new ideas a scientist can only use his own private time. There are a lot of scientists, but most of them do conventional perfectional researches of well-known ideas and small improvements of them, to ensure a good career path. All countries are funding science and research, but they do not usually fund new ideas or concepts. Rather, they assimilate known new technology, often developed in other ecosystem-countries. The net funding for radically new concepts and ideas are close to zero in the world as a percentage of gross funding. Break-through funding, practically-speaking, almost does not exist!

In all countries the composers, writers, artists receive a royalty for performance of their musical compositions, books and artworks. Why must scientists gift their hard work to the world, as they labor on new concepts, ideas, theories, and equations for computations? It would be just as if companies making millions from a newly invented method of computation would pay a small $(\$ 1000)$ royalty for author, without the bizarre legal structure where the only people with assured income from innovations are the readily-despised lawyers. Oddly, in the USA at every known level of governmental over-sight, administration and law-formulations, most of the professionalized politicians are derived from the class of persons known as "attorneys"- them and realtors!

\section{How STUDIES OF INNOVATION}

The development of any new concept and idea can be presented in four essential stages (figure 1). Efficiency, $E$, is possible profit, $P$, divided by cost, $C$, of realization.

$E=P / C$.

The innovation development has four stages:

1. The first stage is discovery of new concepts or idea. That stage includes an appearance of new idea and INITIAL RESEARCH of its possibilities and main conditions that are requisite for its practicability, initial proof of reality. A person can be only author of a new concept or idea if he/she made initial research and showed that this idea may become a future technical reality. A person who ONLY gave the idea (point 0 in Figure 1) is NOT its author because it is easy to produce a lot of ideas that are beneath or beyond realization. For example, the fantast Jules Verne (1828-1905) penned his famous book about the first manned flight to the Moon using a truly huge metal cannon cast in situ in the ground of Florida, USA. Is he the author of the idea for manned flight to Moon employing a big gun? No. Even primitive research shows that a human cannot tolerate the acceleration that is caused by this method, where the vehicle is a cannonball.

The first stage is ONLY theoretical; strong individual and talented enthusiast in own time without any support because unknown concept or idea cannot be in government or company plan.

2. The second stage started after publication or public announcement of the primary idea during a scientific conference. Other researchers join the investigation of the new idea and make more detailed researches. Most of this new idea research is theoretical, and only a small part may be experimental.

3. The third stage includes the production of appropriate experimental examples, an early form of materialization.

4. The fourth stage is actual production of marketable versions of the idea.

We show the development of one innovation (curve 1 in Figure 1). However, any concept exhausts itself and its inherent efficiency possibilities over time. The new concept (idea) appears which promises even more efficiency (curve 2 in Figure 1). Conventionally, in initial time a new concept has less efficiency than a highly over-developed old idea, but as refinements occur in the future, the innovation efficiency becomes significantly more than the old idea.

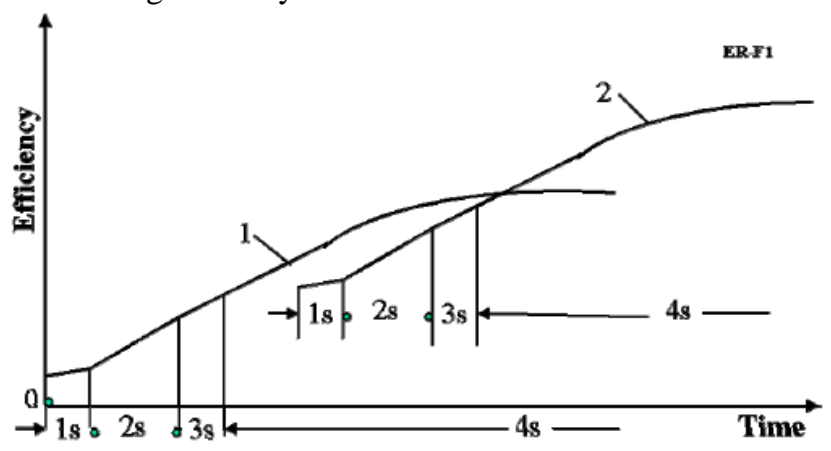

Fig. 1. Four-stage innovation development.

For example, the original idea of a vehicle was startlingly original: People had the idea to connect a vehicle to a horse. Later they invited a motorized vehicle. Then they developed 


\section{International Journal of Engineering and Technical Research (IJETR) \\ ISSN: 2321-0869 (O) 2454-4698 (P) Volume-8, Issue-11, November 2018}

aircraft. At present, humanity is developing space transiting vehicles. People laughed at the first automobiles; the first airplanes were captured collapsing in amusing old movies; the first rockets tended to explode. What American can ever forget the USA's "Flopnik"? But as they matured, they opened - literally — new worlds of possibility.

\section{CRITERIE OF SCIENTIFIC WORKS}

There are two main simple criteria which allow recognition of the difference between true scientific research and that of some pseudo-scientific works by educated or merely clever persons:

1. Author in special paragraph or article conclusion must enumerate: What is new (unknown before!) he/she offered and/or made in work offered? That may be a new concept, an idea, multiple innovations, new mathematical models (equations), new non-conventional result of computation, new design of old or well-known macro and micro object (show its advantages), et cetera.

2. The author must DETAIL all his computation (equations and their receiving!) and initial data, which ALLOW to repeat (checkup) his new equation and computation. If he offered new project, he must estimate the its cost.

If offered idea, research and innovation are close to old or known idea or research, the author must enumerate all difference of his idea, innovations and results from earlier works (What NEW he/she offers/made in his/her work). If nothing on the list is actually new, that means the presented work is just idle talk.

If author does not give the proof of the new equations, full data for computation, he deprives other scientists the means to check his equations and computations and the value of these equations and computations are virtually zero. That means the author(s) is afraid to let his/her work to endure a thorough examination.

The work offered the new macro-projects must contain the estimation of their cost. Without this estimation, the value of scientific work is very low.

In last time it appears very much "scientific" works which are presented as results of funded scientific research for government organizations. That means the burdened taxpayers pay for these works. The Scientific Committee of Auditing "Science", a member of the organization "Citizens Against Government Waste" (CAGW) [2] applied these simple criteria which show: that is scientific or pseudo-scientific work? Those criteria also allow conventional or especially well educated people to recognize pseudo-scientific works (see details in [3] http://auditing-science.narod.ru

http://www.geocities.com/auditing.science/,

http://NASA-NIAC.narod.ru).

There is the third criterion which is applied ONLY to works funded by Government:

3. If this work is funded by Government (taxpayers), the sum of money received by any author (or a research organization) must be made public!

Note, sometimes the author(s) announce: this work was supported by (Government or funded by Government) organization. But if they did not show the exact monetary sum of "support", that means the reader can understand this work was done without spending any taxpayer money.
The sum allows other scientist (and interested people) to estimate the difference between the real cost and payment for the presented work.

Most taxpayer-funded works run by Government departments and agencies do not satisfy this simple criterion. Why? Most likely, because these so-called "researches" are really worthless pseudo-scientific products! The grant is received on the quiet (by backstairs influence). Especially, in this instance, the readers can see it in NIAC (NASA INSTITUTE FOR ADVANCED CONCEPTS. See below) where former director Mr. Robert Cassanova and this defunct group, probably, stole more than 60 millions of USA taxpayer money (see details in [2] http://auditing-science.narod.ru and

[3], http://NASA-NIAC.narod.ru ).

\section{ORGANISATION OF SCIENTIFIC RESACHES}

\section{Government Relations}

Currently, the most important First Stage is the most difficult situation. No Federal or reliable private-sector funding, no extraneous technical support of any kind. This work can be done ONLY by individual enthusiasts and at one's own expense in time and money. Funding of the new perspective concept or idea is needed AFTER its initial theoretical research by an encompassing system of awards and prizes. For example, what NIAC should have been was an agency funding this difficult stage where seed-money is hard to come by (see below in section on NIAC).

\section{Recommendations:}

There is only one solution of this macro-problem - the United States of America's Federal Government must install a series (3 - 5) of special national Government prizes (awards of about $\$ 100 \mathrm{~K}$ should be sufficient) in every important scientific field (space, energy, computing, biology, physics, et cetera.) for new-concept scientific researches that are:

(1) Given ONLY for new concepts and ideas developed by author and published or presented in sufficient qualifying detail at a scientific conference or on the Internet (stage 1 in Figure 1).

(2) The awards must be given ONLY to qualified individuals.

(3) The competition must be OPEN, advertised widely in public notices. ALL contenders and their work and proposals announced BEFORE any awards.

(4) The awarding Committee must be from independent well-known scientists in given field.

The same awards may be also in stage two (developing new concept or idea by non-author of this idea if the author of idea is awarded; or non-author make significant innovations which develop or solve problems important for progress this idea). In stage three the grants can be given ONLY for experiment or model.

\section{NIAC (THE "NASA INSTITUTE FOR ADVANCED CONCEPTS")}

The non-experienced reader objects - there exists NIAC (NASA Institute for Advanced Concepts) that must support new concepts and ideas in aerospace.

But millions of American tax dollars were awarded by NIAC Director Mr. Robert Cassanova for theoretical works before 
they were ever presented to an established scientific society! As a result, the applicant received money before researching and presented "research" that was more an exploration of an idea with potential for revolutionary discovery than an actual development of the idea itself.

In other places awards are given for well-known published scientific works in OPEN competition. It is impossible, for example, that the Nobel Prize for Physics would be given for merely promising to create a epoch-making discovery.

Mr. Cassanova (NIAC) announced that every proposal is reviewed by 6 reviewers ( 3 internal +3 external reviewers), but he refuses to identify or present these reviews. Why?

He did not send the most obvious and really revolutionary proposals to any reviewers. He was afraid, apparently, to show them even to his marionette NIAC Research Council (Chairman Mrs. Robert Whaterhead, Dava Newman (MIT), T. Wang, C. Bowden, L. Goff, et al.).

What kinds of proposals are awarded money supports by $\mathrm{Mr}$. Cassanova?

An important part of the answer to this question can be easily found by the reader at a website: http://NASA-NIAC.narod.ru and others.

Overview: The NIAC spent more 60 millions USA dollars during eight years of its existence, but they did not really put forth any really new concepts or ideas! Most NIAC final "research" reports are idle talk (no scientific results, no pre-production models, no correct scientific report, the final reports content a lot of scientific mistakes, and so on). For example, the final reports don't have any scientific results: Space Elevator (award about one million dollars), Bio Suit (awards about one million dollars), Chameleon Suit (award about 1 million dollars), Weather Control (awards about one million dollars), Winglee M2P2 MagSail (award about two million dollars), Cocoon vehicle (work contains only scientific mistakes), anti-matter sail (empty useless non-scientific seven page work), and so on ad nausea (see Final Reports in http://NASA-NIAC.narod.ru ).

For example, Mr. Robert Cassanova awarded four million of dollars to the following persons: Howe S., Colozza A., Nock $K$., Cash W., Dubowsky S. He also awarded three or four times millions of taxpayer contributions to these persons: Hoffman R. Maise G., McCarmack E., Rice E., Slough J. Kammash N., Winglee R., Newman D.

The Science Committee of the organization "Citizens Against Government Waste" (CAGW) awarded NIAC and Mr. Cassanova the "Pseudo-Nobel Prize-2005" (and "Pseudo-Nobel Prize-2006" for wasting millions of taxpayer dollars by pseudo-scientific works (GOTO: http://auditing-science.narod.ru ).

\section{Recommendations:}

The President and Congress of the United States of America, needs to, and must, thoroughly investigate the NIAC situation and remove, NASA and USRA leaders who allow any abuse and corruption on their watch. The Science Committee of CAGW stands ready to present to a Special Investigation Commission the documents that confirm the statements presented and outlined in this article.

In this saddening and costly national situation, it is the best decision, to stop the wasteful and ineffective financing of NIAC and pass their functions to Independent Committee created from well-known scientists, or NASA can create its own Committee from eminent volunteer scientists or to pass selected managerial functions to the National Science Academy, or National Science Foundation and to send awards only to finished scientific works in OPEN competition, or pass these vital functions to the growing and historically relevant and important International Space Agency Organization (http://www.international-space-agency.org) which would be better suited, and able, to stimulate, enable, and promote advanced space launch, propulsion, power, orbital, and planetary grant disbursements, $\mathrm{R}$ and $\mathrm{D}$ and implementation. This is based on an ever-increasing need for global cooperation, collaboration, common effort, and universal viewpoint. The International Space Agency's Directives, Charter, Purpose, Goals, and Certificate of Incorporation reflects this reality far better than the USRA or NIAC directives or charters. The many millions in Government-dispensed tax monies and private sector money and other relevant resources would be better used under the management and oversight of the International Space Agency Organization.

The CAGW Science Committee has available already an offer to NASA for a detailed plan on how to improve the work of NIAC, making it more open and its product more useful.

This plan includes three conventional conditions:

(1) Independent selection Committee having widely-known E-mail address.

(2) Open competition with publication of all nominated scientific works on Internet, including assessments made by scientists before any funding awards.

(3) Awarding ONLY actually achieved, not speculation about, scientific works not supported from other sources.

\section{Discussion}

The CAGW Science Committee considered, in detail, seven of about two hundred awards made by Mr. Robert Cassanova (GOTO: http://auditing-science.narod.ru ). Amazingly, 90\% of the "final reports" are just idle talk giving the impression to readers that there are NO talented scientists in the USA! That means, obviously, that the system of funding and awarding of scientific works is wrong. Mr. Cassanova is a university system employee and he evidently tries strenuously to fund his friends and protégés within his system of work. However, universities take the funded money and do not pay them over to professors who receive their fixed salary. Often, a professor is overloaded by lectures, direct work with talented students and ordinary classroom examinations. Such a person does not have time or the possibility to make serious research that requires huge efforts and much time. That's why he/she wrote the idle talk report, pseudo-scientific work!

The USA found the best solution of this problem - one sends scientists to government research centers or laboratories and they work full time 1-2 years on a problem there, shielded from busywork. Government centers and laboratories must directly invite the needed scientists without going through favored groups such as National Research Council (NRC) and ORAU (Oak Ridge Associated Universities). That would save much money and stop favoritism toward friends and weak scientists-- often non professionals in a given field of study. The Laboratory scientists know well the talented scientists in his field and they must solve what scientists must be invited.

\section{Conclusion}

The best way is to withdraw this function and this money from NASA-NIAC-USRA, pass them to a special government 


\section{International Journal of Engineering and Technical Research (IJETR) \\ ISSN: 2321-0869 (O) 2454-4698 (P) Volume-8, Issue-11, November 2018}

committee (or the National Academies, or ISA) including famous and reputable scientists and to award the published works (researches) containing new concepts, ideas, inventions, and innovations. Make it an open competition! In 2007, after critics in international press spoke, after many letters from scientists in Government, Congress, the NASA stopped funding the NIAC and discharged Mr. Robert Cassanova. Now, the Federal Government must request the organizations presented the pseudo-scientific works (and Mr. Cassanova) to return the taxpayer's wasted money.

\section{FELLOWSHIP AND NRC (NATIONAL RESEARCH COUNCIL)}

Government created the good initiative - temporary attract the talented scientist for solving the difficult scientific problems (Research Association-ships). The NRC decided to use it for self profit. That received the right to select of candidates (main aim - to be the moderator at sinecure). That allows to take many money to self (NRC employees and NAS), promotion friends (Fellowships), create from NRC the charitable organization for untalented scientists but useful people.

Example, A.A. Bolonkin knows a well-known scientist - he has, so far, had a 30 year-long experience with the acquaintance, authored more than 170 scientific articles and books and tens inventions in given field. He developed the new method, contacted with Government laboratory. The laboratory gave an excellent review in his proposal. He sent the application to NRC. NRC program administrator Mr. E. Basques informed applicant: NRC did not present his proposal to the (2007) NRC Pier Review, as applicant has a low a scientific score (7.4). The NRC deprived him to apply his proposals in during one year??!! He asked Mr. Basques: send to him detail computation of his score; explain - why his score is so very low; how much years of experience, scientific works and inventions he must has for admission to any NRC review; how much years of experience, scientific works and inventions the selected candidate have; who is chair of NRC and NRC Advisory Committee. Mr. Basques answered, that such information are secret!

Very early in the game, NRC was accepting three different proposals from just one applicant in one Panel review and had four Reviews in every year. That was true competition which allows the talented active scientists to promote new ideas and develop America's technology. But now Mr. E. Basques accepts ONLY one application per year from one applicant including the candidates who he did not admit to review! He converts the NRC, scientific COMPETITION to charitable organization for untalented, dull scientists, his friends and other such useful persons.

We call your attention to the following abnormal economic situation. The Air force, Army, Navy, NASA and other well-known USA government scientific laboratories are staffed with leading scientists in their various fields. Laboratories can estimate and select the new ideas, concepts and innovations. They do not need a skewing mediator (NRC) for selection of proper, potentially very productive research candidates. The NRC mediator produces ONLY additional expenses (up to 50\%) and imposes on such laboratories and facilities the good friends of a NRC moderator, but the bad scientists contracted make few useful or worthwhile discoveries.
We have same situation, when the mediator (NRC) stands between seller (scientist) and customer (Government Research Laboratory). When the laboratory wants to hire the scientists, the moderator stops buying, request the big moderation payment and sale (imposed) customer the other, own, bad goods.

Conclusion: The Associate-ship Government Program is a truly excellent and economically useful idea, but Government Research Laboratories do not need a NRC moderator to function successfully. They know best the specialists in their active investigational fields than any over-paid, biases current NRC bureaucrat and they can select the best scientists without NRC moderating, thus saving millions of taxpayer dollars and, at the same time, greatly accelerate America's further technical progress.

\section{PUBLICATIONS}

There are well-known organizations such as the American Institute of Aeronautics and Astronautics. One performs great works, organizes aerospace conferences and publishes a series of aerospace journals. But it doesn't have support from government and NASA and it became a strictly commercial organization. For example, the cost of participation in AIAA conferences is very high. That means only employees of government and big organizations can take part in scientific forums. But, almost by definition, they will display only conventional R\&D plans of the type the system currently favors. The new revolutionary ideas and researches are made by talented individuals, enthusiasts in their free time. They can make a revolutionary research, but they do not have much money (some thousands of dollars) for payment of trip, hotel and conference fee. Literally, the USA loses these revolutionary researches.

Editors of AIAA journals do not get a salary for their arduous efforts. That means they want to see their name in every copy of journal, but they do not want to work as editor. They pass an article to a reviewer, and pass the review to author. That function can be done via computer. Some of them have allegedly converted their journal to essentially a private edition for their friends and protégés. For example, all 20 revolutionary researches which were published in the recent comprehensive book "Non-Rocket Space Launch and Flight", Elsevier, London, 2006, offered for publication in AIAA "Journal of Power and Propulsion" (JPP), but all were rejected by editor-in-chief Vigor Yang as researches were written in a non-American style and having poor English diction. What is "American style" he cannot explain, poor English-- the readers can see the book and decide: Is it a sufficiently important reason in refuse revolutionary innovations? From notes of Vigor Yang, it is seen he has poor knowledge of extant aerospace and vehicle propulsion systems. For some last years the "JPP" have not published any revolutionary ideas, but published many articles having serious scientific mistakes. The same situation with AIAA "Journal of Spacecraft and Rockets" (Editor-in-Chief Vincent Zoby).

It is a bad situation, that the USA has only a single journal about power and propulsion system or spacecraft and American authors must publish new ideas and researches in journals abroad.

It is bad that commercial publishing houses do not want to publish scientific literature, because it is not profitable. As a 
result, the scientific literature (and text-books) are very expensive and prohibitive not only for students, but for scientists.

It is bad that there is no free scientific Internet library (which would pay the government back by factors of 1000 in terms of net scientific development generated) to enable individuals of talent and enthusiasts to pursue their researches by using open sources of data and other information.

It is bad that the AIAA requests about $\$ 1000$ for every publication in its journal and sells every scientific article for $\$ 10$.

\section{Recommendations:}

(1) The USA must have minimum two rival journals in every scientific field. (These may be Internet journals). Every journal must have an Appeal Commission where author can complain if he/she does not agree with editor's clearly stated reasons for article rejection.

(2) Every National Conference must have a small fund for supporting the individuals presenting revolutionary research and give them possibility to address a meeting.

(3) The US Government and the NASA must support with appropriate funding the points 1-2 above (scientific journal and scientific conferences), the AIAA (and all big old Scientific Societies), the scientific publishing houses, the free scientific Internet library.

(4) The AIAA (and all big old Scientific Societies) must freely publish on the Internet all manuscripts presented in AIAA Scientific Conferences. (Paper copies, of course, are its business and may be charged for as the publishers pleases).

(5) The government must create the free Internet Library of the technical, mathematic, physic textbooks.

The Government and country lose more on the obstacles outlined above, which stop the generation and filtering and developing new ideas, than the output of the most talented individual researchers of this generation. The loss is incalculable and should stop immediately.

\section{IMPROVING PATENTING}

\section{9-1. Disadvantages of modern patenting in the US}

The main disadvantage is the high cost and duration of the patent. The total expenses of an individual inventor for obtaining a patent are tens of thousands of dollars and several years of exhausting correspondence with the Patent Office (PTO). Even after obtaining a patent, an individual inventor (in most cases, they have a low income) must pay the PTO more than \$3,000 for "maintaining" the patent, otherwise the patent will expire. Any company is more profitable to wait 3.5 years and spend this time developing and testing a sample, rather than spending money on buying or leasing a patent.

As a result, about $98 \%$ of inventions are unsold, the inventor remains without a livelihood and permanently loses interest in creativity. At present, the PTO has turned into a powerful pump for pumping money from the naive poor individual inventors, from their patriotic desire to help the country and technical progress. To obtain a patent, the author (Micro-Entity) must pay tens of points for \$ 70-15000 each. The desire of the PTO to swing money sometimes takes idiotic forms. For example, the PTO requires paying \$ 70 for having accepted a provisional application and stored it (without any consideration) in the computer for 12 months. It should be noted that Google, the Archive and most major libraries accept for free access articles, books, patent applications, music for an unlimited period of time and get the date of admission.

As a result, the PTO has become a giant brake on the way of the technical progress of the United States. The PTO cuts off the bulk of the low income individual inventors. True for large firms, high prices for patenting are not a hindrance. But all firms when they come to work require that engineers and highly qualified employees sign a contract with them, that all their inventions made during the period of work at this firm are transferred to the company for free. This prevents the creation of truly valuable inventions. The most surprising thing is that the US bureaucracy does not care about the interests of the country. Working in NASA as a senior researcher, I made many debates in the field of thermonuclear energy, cosmonautics, nuclear weapons. Being grateful to the United States that America has sheltered me as a political refugee from the USSR, I wanted to register and pass the important US inventions to the US Government without a shiver. The only thing I asked was that the state PTO did not require me to pay for registration of patents, because I was not able to pay them. And what did the NASA management answer me? That they will not register inventions that are not used locally within their local organization. I must apply to private companies (???). And what did the powerful firms that fulfill NASA's orders respond? That I must sign the Agreement that I will never ask them for any reward for using my inventions. Only in this case they will CONSIDER my inventions.

And how did the Government of the USSR do it? It registered all inventions free of charge and took them to itself, issuing only the Author's Certificate to the author. True, the large organization in which the author worked paid the author a miserable reward (1/5 of the monthly salary), and the state promised (in case of mass use of the invention) to pay a reward: a maximum of 20,000 rubles (about $\$ 2,000$ at the exchange rate of the black market), but never it did not pay. I did not want to give important military inventions to the Communists, for I understood the criminal aims of the Government of the USSR. For this I was persecuted in the former Soviet Union.

Unfortunately, in the USA I encountered the reverse problem: the state (PTO) creates huge obstacles to technical progress. In this connection, the question arises:

\section{9-2. Do we need such a PTO?}

Let's see how writers and musicians solve the problem of intellectual property. They publish their works without any patenting. And if someone starts using them for profit without the permission of the author, then they bring the case to court and demand compensation. Why should not this practice be extended to inventions? You place your application for invention on special free sites (Google, Archive.org or PTO) that put the date of placement. The application is formalized according to the Rules of the PTO (history of the invention, detailed description with figures, claims, patent research, etc.). You can add to it the terms of transfer, leasing or purchase. If someone began to use this application without the permission of the author to make a profit, then the author can sue and demand a reward. Such a Registered Application can be submitted by the author to the PTO during the period of validity of the patent 


\section{International Journal of Engineering and Technical Research (IJETR) \\ ISSN: 2321-0869 (O) 2454-4698 (P) Volume-8, Issue-11, November 2018}

(20 years). And only then the PTO can demand a fair payment for the examination of the application and the issuance of the patent. The PTO acts in this case as a primary independent expert. If the author does not agree with the decision of the PTO, he can refer the case to the Arbitration Committee of the PTO or appeal to an ordinary court. The low come inventors over 65 years of age having only SSI can patent for free, but the State receives all rights to the acquisition and pays a small fee. Payments for the "maintenance" of the patent should be canceled.

The State Committee for Inventions is needed, where authors of inventions that are important for the defense, security or technical progress of the country can apply. If the experts recognize the invention as such, then the invention is declared state property or secret, the PTO patent this invention for free, the author is deducted $1 \%$ of the cost of products using this invention, and the Committee (or PTO) $0.5 \%$ for the content of the Committee (PTO).

\section{9-3. Brief Summary. Suggestions:}

1. The application for the invention is drawn up under all Rules of the PTO (history of the invention, detailed description with figures, claims, patent research, etc.). Inventor can add to it the terms of transfer, cost leasing or purchase. The application is posted on an open, widely known website (Google Patent, Archive.org, http://intellectualarchive.com, PTO or special web side) with free access, which puts the placement date. Give ordinary courts the right to accept statements of claim from the author (or his close relatives in the event of his death), if promulgated non-patented inventions for violation of intellectual property (somebody is using given invention for profit).

2. During the period of validity of the patent (usually 20 years), the author can submit an application to the PTO for examination and issuance of a patent. Only then he pays a fair PTO fee for the examination of the application and the issuance of a patent.

3. The total maximum fee cannot exceed $\$ 100$ for individual inventor. Payments for "maintaining" the patent (Maintence Fees) should be canceled.

4. The inventor over 65 years of age having only SSI can patent for free.

5. The State Committee for Inventions (or the department in the PTO) is needed, where authors of inventions that are important for the defense, security or technical progress of the country can apply. If the experts recognize the invention as such, then the invention becomes state property or secret, the PTO patent this invention for free. In the future, the author will get $1 \%$ of the cost of products using this invention, and the Committee (or PTO) $0.5 \%$ for the content of the Committee (PTO).

All PTO profits should be used to support individual inventors with low income and for inventor over 65 years of age.

\section{TOTAL SUMmary. FinAl RECOMMENDATIONS.}

Current system organization and funding of science researches is not efficient, especially for NRC, PTO, NIAC, NASA, DARPA, DOD, AF, SBIR and the NSF. They need re-organization. Main components of this reformation must be the following:
(1) The unwise and wasteful practice of advance funding of primary theoretical researches must be stopped and changed to OPEN competitions in any given field and in given topics.

(2) Government must install 3-5 annual Government Prizes (about $\$ 100 \mathrm{~K}$ ) in every important field of science (space, aviation, computer, physics, biology, energy, etc.) for important THEORETICAL achievements made by individuals. Practical results will flow from these if such are forthcoming from enthusiasts; but the way forward must be pointed out. It takes genius to do it, and genius needs its physical as well as spiritual rewards!

(3) The company using new methods of computation must pay small ( $\$ 1000$ or less) royalties to the authors for every licensing use.

(4) Provisional Application (PA) storage charges shall not be charged. The term of the Provisional Application must be equal to the full term of the patent ( 20 years). The PTO may require a fee (no more than $\$ 100$ per share only when the applicant requests to examine the PA for the grant of a patent. The validity period of a patent is calculated from the date of its open publication on the Internet. The date and link to publication is reported to the PTO.

(5) Must be also the additional form free registration inventions without PTO (PTO examination and PTO fee).

(6) NASA must be divided into at least two independent rival organizations.

(7) The main method funding of research must not be funding through Universities but it must be the work of University scientists done during 1-3 years 'sabbatical' as Fellow researchers in big Government laboratories. The NRC must be closed and Government laboratory straight invite the needed scientists.

(8) NASA, DARPA, Government laboratories must engage a head and main specialists of every project in OPEN competitions, preferably the authors of project (proposal) and scientists who made the main contributions in the project idea or concepts.

(9) The Government must support adequate scientific journals, publishing houses, free Internet scientific libraries; individual scientists should be aided to presented important researches to scientific national conferences.

(10) Government must make special small rates apply $(<\$ 100)$ to individual inventors, free patenting of important for DOD and National defense inventions and to use all PTO profit for support of individual inventor programs important for DOD and the USA. See also [4]-[6].

\section{REFERENCES}

[1] Robert Friedel, A Culture of Improvement: Technology and the Western Millennium, MIT Press, 2007.

[2] http://NASA-NIAC.narod.ru .

[3] http://auditing-science.narod.ru .

[4] A.A. Bolonkin, New Concepts, Ideas and Innovations in Aerospace, Technology and Human Science. Nova Science Publications, New York. 509 ps. ISBN-13:978-1-60021-787-6.

[5] Richard Drayton, Nature's Government: Science, Imperial Britain and the 'Improvement' of the World (2000).

[6] David Pressman, Patent it Yourself, NOLO Press, Berkeley. 7-th Edition 